\title{
Central venous pressure in the ventilated neonate
}

\author{
Jonathan R Skinner, David W A Milligan, Stewart Hunter, Edmund N Hey
}

\begin{abstract}
As there is no other measurement of right ventricular preload, central venous pressure (CVP) measurement provides unique and important haemodynamic information. CVP is not measured routinely in neonatology and there is a shortage of data in the ventilated neonate.

CVP was measured in 62 ventilated neonates. Thirteen had respiratory disorders (28-42 weeks' gestation, birth weight 860-4390 g) and 49 had congenital heart disease (birth weight $1600-4500 \mathrm{~g}$, age 0.5-30 days). Data from other case reports are also presented. In the babies with respiratory distress, a value of zero was associated with clinical evidence of hypovolaemia and negative values, common in the unventilated neonate, did not occur in those who were ventilated. Values over $7 \mathrm{~mm}$ $\mathrm{Hg}$ were found in babies with evidence of myocardial dysfunction or persistent fetal circulation but were also found with transmitted high intrathoracic pressure, such as with pneumothorax. In the babies with congenital heart disease, values mostly lay between 4 and $8 \mathrm{~mm} \mathrm{Hg}$. Values outside this range, particularly above $8 \mathrm{~mm} \mathrm{Hg}$, were usually associated with profound metabolic acidosis, suggesting circulatory failure.

While the main use of CVP measurement is in trend analysis, this report suggests that single measurements can be of value, though correct interpretation will depend on the context in which they are made.
\end{abstract}

There has been a great deal of interest recently in the non-invasive assessment of haemodynamic function in the neonate, perhaps at the expense of invasive methods. During an evaluation of right heart pressure measurement using the Bernoulli equation, ${ }^{12}$ it became apparent that there is little published data available on central venous pressure (CVP) in the sick neonate, and only limited data in the healthy neonate. This is particularly surprising as the myocardium of the sick neonate is highly dependent on an adequate preload, ${ }^{3}$ and functions against a high afterload in the shape of pulmonary hypertension.

CVP is not monitored routinely in neonatology and there is no non-invasive measure of preload. There is a shortage of such data in the ventilated neonate, and indeed some of the reference manuals of neonatal intensive care barely mention the subject. Most available data were obtained from healthy babies, and these values (of around -2 to $+4 \mathrm{~mm} \mathrm{Hg}$ ) ${ }^{4-7}$ may not be relevant to the ventilated baby. In order to try to obtain 'normative reference data' for the ventilated newborn baby we have reviewed the available published data and assembled further case material from 62 neonates. Group 1 consisted of 49 babies with congenital heart disease undergoing cardiac catheterisation and group 2 of 13 babies with respiratory disease who had CVP measurements while undergoing intensive care.

Patients and methods

GROUP 1: BABIES WITH CONGENITAL HEART DISEASE

Data were available from 49 neonates with a variety of congenital heart defects who were catheterised at the regional cardiothoracic unit in Newcastle between 1977 and 1979. This represents an unselected sample from a period before the routine clinical use of cross sectional and Doppler echocardiography in neonatal cardiac diagnosis. Median age was 5 days (range 0.5-30 days); 29 (59\%) were less than 8 days old. Mean weight was $3300 \mathrm{~g}$ (range 1600-4500).

All of the babies were ventilated and under general anaesthesia. Measurements were made using a strain gauge with either a BentleyTrantec or a Truck transducer. Signals were transmitted via isolation amplifiers at the foot of the bed to pressure amplifiers in the main console. Recordings were made with a Siemens Elema Mingograph chart recorder and were reported by one of two consultant paediatric cardiologists.

GROUP 2: BABIES VENTILATED FOR RESPIRATORY DISEASE

Values from 13 neonates ventilated for a variety of respiratory disorders were collected between 1988 and 1991. Gestation was between 28 and 42 weeks and birth weight between 860 and $4390 \mathrm{~g}$. Further details are given in the results.

Central venous access was obtained via the umbilical or the internal jugular vein. Measurements were supervised by a clinician (JRS or DWAM). A Gould P50 minidome transducer was used, connected to a Kontron Supermon pressure module.

In both groups, the catheter tip was in the right atrium and zero calibration was at the mid thorax, corresponding approximately to the level of the tricuspid valve.

\section{Results}

GROUP 1: BABIES WITH CONGENITAL HEART DISEASE

The results are summarised in table 1 and the

$y_{1}$
$y_{1}$

\footnotetext{
NE2 3BD.

Accepted 8 November 1991

Correspondence to:

Department of Child Health,

Princess Mary

Maternity Hospital,

Neonatal Unit,

Newcastle upon Ty

David W A Milligan

Nowcastle upon Tyne

Cardiology,

Freeman Hospital,
}

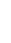


Table 1 CVP measurements ( $\mathrm{mm} \mathrm{Hg}$ ) from 49 neonates with congenital heart disease, while ventilated and under general anaesthesia

\begin{tabular}{lcccc}
\hline Diagnostic category & $\begin{array}{l}\text { No of } \\
\text { babies }\end{array}$ & 'a' Wave & ' $v$ ' Wave' & Mean \\
\hline (1) Persistent fetal circulation & 3 & $12(6 \cdot 0)$ & $10(6 \cdot 0)$ & $8 \cdot 3(3 \cdot 1)$ \\
(2) Obstructive left heart lesions $\dagger$ & 15 & $11 \cdot 3(4 \cdot 2)$ & $10 \cdot 6(4 \cdot 6)$ & $8 \cdot 9(3 \cdot 2)^{*}$ \\
(3) Remainder & 31 & $8 \cdot 0(3 \cdot 5)$ & $6 \cdot 4(3 \cdot 6)$ & $5 \cdot 2(2 \cdot 5)^{*}$ \\
Whole group & 49 & $9 \cdot 3(4 \cdot 3)$ & $7 \cdot 7(4 \cdot 4)$ & $6 \cdot 5(3 \cdot 2)$ \\
\hline
\end{tabular}

${ }^{*} \mathrm{p}<0.001$, comparing groups 2 and 3 .

'a wave' represents atrial contraction, ' $v$ wave' represents venous filling of the right atrium. tCoarctation $(n=12)$, aortic stenosis $(n=1)$, and hypoplastic left heart syndrome $(n=2)$.
O Coarctation + VSD

$\Delta$ Hypoplastic left heart

- Persistent fetal circulation

- Transposition + VSD

$\odot$ Normal heart

Arterial trunk

$\Delta$ Other

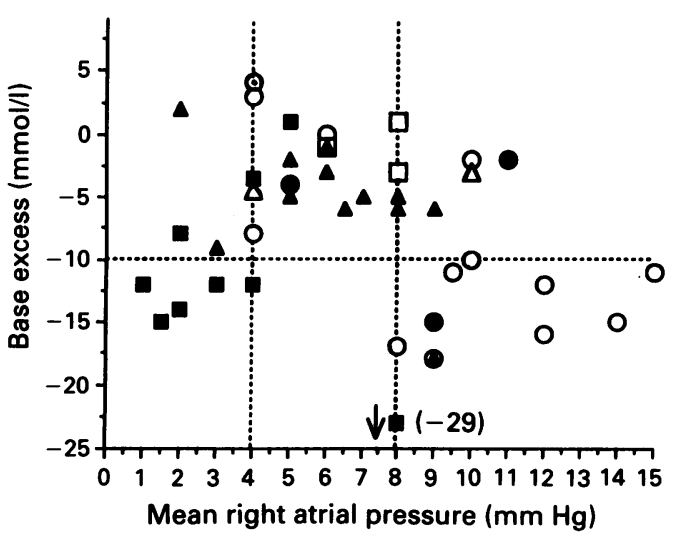

Central venous pressure in 42 neonates with congenital heart disease plotted against the base excess from a concurrent arterial blood gas sample. The overlying lines highlight values between 4 and $8 \mathrm{~mm} \mathrm{Hg}$, and base excess values of $-10 \mathrm{mmol} / \mathrm{l}$ or more (see text). VSD=ventricular septal defect. figure. No values below $+1 \mathrm{~mm} \mathrm{Hg}$ were encountered and only five babies had values of 1 to $2 \mathrm{~mm} \mathrm{Hg}$. Of these five, three babies had an appreciable metabolic acidosis $(\mathrm{pH}<7 \cdot 22$, base excess $>-8 \mathrm{mmol} / \mathrm{l}$ ), and all three had transposition of the great arteries with ventricular septal defect. At the other extreme, there were 13 babies with a CVP of over $8 \mathrm{~mm} \mathrm{Hg}$. All but two (who had tricuspid atresia or pulmonary atresia with ventricular septal defect) were in overt cardiac failure; eight had aortic coarctation, two had persistent fetal circulation, and one had a hypoplastic left heart. Nine of these 13 babies had a severe metabolic acidosis. Twelve babies had coarctation: eight had a CVP of more than 8 $\mathrm{mm} \mathrm{Hg}$ and seven of these were profoundly acidotic (as was the only baby with a CVP of 8 $\mathrm{mm} \mathbf{H g}$ ) indicating circulatory failure. The other three babies with coarctation had CVP values of 4-6 mm $\mathrm{Hg}$ and were not acidotic. There were 22 babies with a CVP of $4-8 \mathrm{~mm} \mathrm{Hg}$ and available blood gas results and only three were significantly acidotic (two had CVP values of $8 \mathrm{~mm} \mathrm{Hg}$ and the other of $4 \mathrm{~mm} \mathrm{Hg}$ ).

GROUP 2: BABIES VENTILATED FOR RESPIRATORY DISEASE

The results are summarised in table 2, though this presentation does not demonstrate the most useful feature of CVP measurement, which comes from serial measurement. However, on all occasions when the CVP was zero, there was clinical evidence of hypovolaemia. In general, higher values were seen in the larger babies, but this observation could be explained by the nature of their illness, rather than size per se, with a preponderance of asphyxia and myocardial ischaemia. Low values, from $0-3 \mathrm{~mm}$ $\mathrm{Hg}$ were particularly badly tolerated in this group. The four babies with uncomplicated hyaline membrane disease who survived had CVP values within a relatively narrow band when clinically stable $(2-6 \mathrm{~mm} \mathrm{Hg}$ most of the time).

Table 2 CVP in 13 ventilated neonates with respiratory distress

\begin{tabular}{|c|c|c|c|c|c|c|c|}
\hline \multirow{2}{*}{$\begin{array}{l}\text { Gestation } \\
\text { (weeks) }\end{array}$} & \multirow{2}{*}{$\begin{array}{l}\text { Birth } \\
\text { weight } \\
\text { (g) }\end{array}$} & \multirow[t]{2}{*}{ Diagnosis } & \multirow[t]{2}{*}{ Outcome } & \multicolumn{2}{|c|}{ Observations } & \multicolumn{2}{|c|}{$C V P(m m ~ H g)$} \\
\hline & & & & No & $\begin{array}{l}\text { Age } \\
\text { (hours) }\end{array}$ & Range & Mean \\
\hline $\begin{array}{l}28 \\
28 \\
31 \\
31 \\
31 \\
32 \\
34 \\
36 \\
38\end{array}$ & $\begin{array}{l}1120 \\
1160 \\
1970 \\
1600 \\
1945 \\
860 \\
2540 \\
3150 \\
3610\end{array}$ & $\begin{array}{l}\text { HMD, PPHT, PIE, ICH } \\
\text { HMD, PPHT, PTX, ICH } \\
\text { HMD } \\
\text { HMD } \\
\text { HMD } \\
\text { IUGR, asphyxia, ICH } \\
\text { HMD, asphyxia } \\
\text { PPHT, myocardial ischaemia } \\
\text { Asphyxia, myocardial ischaemia } \\
\text { NEC }\end{array}$ & $\begin{array}{l}\text { Died } 41 \text { hours } \\
\text { Died } 36 \text { hours } \\
\text { Alive, well } \\
\text { Alive, well } \\
\text { Alive, well } \\
\text { Died } 14 \text { days } \\
\text { Alive, well } \\
\text { Alive, well } \\
\text { Alive, well }\end{array}$ & $\begin{array}{r}21 \\
4 \\
1 \\
18 \\
22 \\
31 \\
1 \\
1 \\
2 \\
24 \\
24 \\
13\end{array}$ & $\begin{array}{c}18-39 \\
4-8 \\
5 \\
13-48 \\
18-40 \\
20-54 \\
82 \\
48 \\
0-1 \\
25-48 \\
49-72 \\
73-85\end{array}$ & $\begin{array}{l}4-9 \\
3-5 \\
- \\
0-5^{*} \\
0-6 \dagger \\
0-10 \ddagger \\
- \\
\overline{0-35} \\
6-11 \\
5-9 \\
3-7\end{array}$ & $\begin{array}{l}7 \cdot 0 \\
4 \cdot 0 \\
4 \cdot 0 \\
2 \cdot 8 \\
2.6 \\
5 \cdot 7 \\
6 \cdot 0 \\
9 \cdot 0 \\
1.5 \\
6 \cdot 8 \\
6.8 \\
5 \cdot 7\end{array}$ \\
\hline $\begin{array}{l}40 \\
40 \\
40\end{array}$ & $\begin{array}{l}4230 \\
3210 \\
3335\end{array}$ & $\begin{array}{l}\text { Asphyxia } \\
\text { PPHT, septicaemia } \\
\text { Asphyxia, pulmonary haemorrhage, } \\
\text { renal failure }\end{array}$ & $\begin{array}{l}\text { Died } 24 \text { hours } \\
\text { Alive, well } \\
\text { Died } 6 \text { days }\end{array}$ & $\begin{array}{r}9 \\
44 \\
63\end{array}$ & $\begin{array}{l}10-18 \\
96-130 \\
67-139\end{array}$ & $\begin{array}{l}4-10 \\
6-12 \\
0-89\end{array}$ & $\begin{array}{l}6 \cdot 8 \\
7 \cdot 8 \\
3 \cdot 8\end{array}$ \\
\hline 42 & 4390 & PPHT, meconium aspiration & Alive, well & 26 & $47-73$ & $2-9$ & $5 \cdot 0$ \\
\hline
\end{tabular}

HMD = hyaline membrane disease, $\mathrm{ICH}=$ large intracranial haemorrhage, IUGR = intrauterine growth retardation, NEC=necrotising enterocolitis, PIE= pulmonary interstitial emphysema, PPHT=persistent pulmonary hypertension, PTX = pneumothorax ${ }^{*}$ One record of zero CVP coincided with circulatory collapse and hypotension at the time of an intracerebral bleed. †Three recordings at zero with poor peripheral perfusion and mild metabolic acidosis; $20 \mathrm{ml} / \mathrm{kg}$ of colloid caused the CVP to rise to $6 \mathrm{~mm} \mathrm{Hg}$ with clinical improvement

† wo recordings at zero with clinical evidence of hypovolaemia.

fUmbilical line used for resuscitation with $30 \mathrm{ml} / \mathrm{kg}$ of colloid. Systolic blood pressure of $30 \mathrm{~mm} \mathrm{Hg}$ rose to $45 \mathrm{~mm} \mathrm{Hg}$; CVP rose from zero to $3 \mathrm{~mm} \mathrm{Hg}$. Later values from jugular line for intravenous feeding when clinically stable on inotropic support. IThree episodes of hypotension/circulatory collapse, all with pulmonary haemorrhage; CVP fell to zero or $1 \mathrm{from} 3-4 \mathrm{~mm} \mathrm{Hg}$ twice, but with the preterminal event CVP rose to $8 \mathrm{~mm} \mathrm{Hg}$, with clinical and echocardiographic evidence of severe right ventricular failure. 
REVIEW OF THE LITERATURE

Preterm babies with hyaline membrane disease Rudolph et al recorded CVP in six babies with hyaline membrane disease; values ranged between $-6.5 \mathrm{~mm} \mathrm{Hg}$ and zero. ${ }^{5}$ In such early studies of hyaline membrane disease the babies were usually unventilated and generating large negative intrathoracic pressures. Because of this influence of intrathoracic pressure, Stahlman et al did not report mean CVP in their studies. ${ }^{8}$ Siassi et al reported a mean CVP of $+1.6 \mathrm{~mm}$ $\mathrm{Hg}$ in healthy preterm neonates and negative values in 12 babies with respiratory distress with values varying from -16 to $+3 \mathrm{~mm} \mathrm{Hg}$. ${ }^{9}$ Six of these 12 babies were ventilated and they were reported to have higher values within this range. Cabal and Hodgman reported that a ventilated premature neonate developed a mean CVP of $12 \mathrm{~mm} \mathrm{Hg}$ with a tension pneumothrax, which returned to $6 \mathrm{~mm} \mathrm{Hg}$ after successful drainage. ${ }^{10}$

Todres et al performed Swan-Ganz catheterisation in 11 ventilated preterm neonates. ${ }^{11}$ In two of these babies CVP was reported; both had hyaline membrane disease and septicaemia. One baby had a CVP of $2 \mathrm{~mm} \mathrm{Hg}$ and the other a CVP of 0-2 $\mathrm{mm} \mathrm{Hg}$. The latter baby was clinically hypovolaemic when right atrial pressure was zero. In another study by Cabal $e t$ al four asphyxiated, ventilated, preterm neonates of 30-34 weeks' gestation with respiratory distress and heart failure were managed successfully with inotropes. ${ }^{12}$ Mean CVP was $12 \mathrm{~mm}$ $\mathrm{Hg}$ at 1 hour of age (before treatment), $6.2 \mathrm{~mm}$ $\mathrm{Hg}$ at 6 hours, $5 \mathrm{~mm} \mathrm{Hg}$ at 12 hours, and $4 \mathrm{~mm}$ $\mathrm{Hg}$ at 24 hours.

\section{Term babies with persistent pulmonary hypertension}

Peckham and Fox catheterised 10 ventilated babies with persistent fetal circulation and found a mean CVP of $6.6 \mathrm{~mm} \mathrm{Hg} .{ }^{13}$ Tamura and Kawano investigated the clinical efficacy of nitroglycerine in the management of heart failure and persistent pulmonary hypertension. ${ }^{14} \mathrm{Six}$ babies had CVP recordings, two were of 32 weeks' gestation and the rest were at term; all were ventilated. The initial mean (SD) CVP was $13.8(6 \cdot 7) \mathrm{mm} \mathrm{Hg}$ falling to $10 \cdot 8(4 \cdot 4) \mathrm{mm} \mathrm{Hg}$ with clinical improvement. However, this was a mixed group of babies: one had Ebstein's anomaly, one had hypertrophic cardiomyopathy, and two had diaphragmatic hernias.

\section{Older babies with congenital heart disease}

Burnell catheterised 131 infants under 1 year of age with congenital heart disease. ${ }^{15}$ Those in heart failure had a mean right atrial pressure of $7.7 \mathrm{~mm} \mathrm{Hg}$ compared with $3.5 \mathrm{~mm} \mathrm{Hg}$ in those without heart failure. Some of the babies were ventilated and some were not.

\section{Discussion}

There is strong experimental evidence that the cardiovascular system in the human neonate is much less able to cope with hypervolaemic and hypovolaemic conditions than the adult. ${ }^{16}$
Hypovolaemic shock, probably an important factor in the development of respiratory distress, ${ }^{17} 18$ is common after perinatal asphyxia or preterm delivery. Early cord clamping can deprive the baby of over $40 \%$ of its circulating volume.${ }^{19}$ Hypotension is known to be associated with an increased risk of intraventricular haemorrhage, ${ }^{20}$ and an early increase in preload by colloid administration may reduce the risk. ${ }^{21}$ In the assessment of all these dramatic haemodynamic changes and interventions it is remarkable how infrequently CVP is measured.

It is clearly difficult to establish 'normal' values for central venous pressure as the optimal filling pressure for any individual is unique and varies with changes in ventricular performance, compliance, and afterload. However, this review would suggest that at least some guidelines can be drawn up and that although the main use of CVP measurement is in trend analysis and in monitoring treatment, some interpretation of initial or isolated measurements can be made. It appears that in the ventilated neonate, a CVP of zero is likely to be associated with hypovolaemia and inadequate right ventricular preload. In term babies with heart failure and pulmonary hypertension higher pressures are found, so a value of $3 \mathrm{~mm} \mathrm{Hg}$ in this situation may also indicate inadequate preload. While values of $2-6 \mathrm{~mm} \mathrm{Hg}$ are 'normal' in clinically stable preterm babies requiring ventilation for hyaline membrane disease, such values may indicate inadequate preload in the bigger baby with pulmonary hypertension. A comparison can be drawn from cardiac intensive care where right atrial pressures of up to $20 \mathrm{~mm} \mathrm{Hg}$ are needed in the infant after right ventriculotomy to correct Fallot's tetralogy, and values within the 'normal range' are associated with inadequate pulmonary blood flow. The failing right ventricle requires an increased preload to maintain output as with decreased contractility a higher end diastolic volume is required to maintain stroke volume. ${ }^{22}$ Values over $20 \mathrm{~mm} \mathrm{Hg}$ are avoided because of the risk of ascites. ${ }^{23}$

CVP values over $7 \mathrm{~mm} \mathrm{Hg}$ usually indicate myocardial dysfunction and/or pulmonary hypertension, but high values need to be interpreted with caution. The measured value may be artificially high due to raised intrathoracic pressure, secondary to pneumothorax or overventilation of compliant lungs. This may be an important factor when therapeutic alkalosis is induced by hyperventilation. The measured value may also be misleadingly low if there is coincident hypovolaemia. It needs to be remembered that CVP is related, not only to the volume of intravascular blood within the venous system and the function of the cardiac pump, but also to intrathoracic pressure. ${ }^{3} 92425$ A more ideal measure, that of central venous filling pressure, could in theory be obtained by subtracting intrathoracic pressure, measured by oesophageal manometry, from CVP but this does not seem to have been attempted in clinical practice as yet.

Todres et al showed that left ventricular filling pressure measured by Swan-Ganz catheterisation is a practical and useful method to 
assess left ventricular function in the neonate. ${ }^{11}$ However, in the newborn there is usually biventricular failure so that CVP measurement can still be of use in babies presenting primarily with left ventricular dysfunction. This was demonstrated by the patients with aortic coarctation in our study: babies with circulatory failure, manifesting as a metabolic acidosis, had higher CVP values (over $7 \mathrm{~mm} \mathrm{Hg}$ ) than those who did not.

Measurement of CVP is not difficult, but it is an invasive procedure which carries potential risks. Is it likely that a non-invasive tool will be able to replace it? At present this seems unlikely. Doppler echocardiography can estimate pulmonary arterial pressure ${ }^{12627}$ and pulmonary flow by monitoring left or right ventricular output. But if pulmonary blood flow falls, what has caused the fall? We can estimate afterload, but is the preload too low or too high? This question is only answered by serial measurement of CVP. An accurate non-invasive measure of blood volume is also still awaited, though an interesting area is the measurement of the circulating peptides atrial natriuretic peptide and arginine vasopressin. Their relationship to circulating volume and atrial distension is still under research. ${ }^{28}{ }^{29}$ However, it seems likely that they will be influenced by a number of variables associated with postnatal adaptation, stress, and ventilation.

CVP values provide unique haemodynamic information, which is of particular importance to the very sick neonate. The principal use of CVP measurement is in trend analysis, but interpretation of initial or isolated measurements in the ventilated neonate assumes special importance during an episode of cardiorespiratory collapse. This review shows that single measurements can be of value, but that correct interpretation of the result will depend on the context in which it is made.

Dr Skinner is research fellow in child health and is supported by the National Heart Research Fund.

1 Skinner JR, Boys RJ, Hunter S, Hey EN. Non-invasive assessment of pulmonary arterial pressure in healthy assessment of pulmonary arterial press
neonates. Arch Dis Child 1991;66:386-90.

Z S̄kinner JR, Boys RJ, Hunter S, Hey EN. Pulmonary and systemic arterial pressure in hyaline membrane disease. systemic arterial pressure in hyal

5 Maayan C, tyal F, Mandelberg A, Sapoznikov D, Lewis BS Effect of mechanical ventilation and volume loading on left ventricular performance in premature neonates with respiratory distress syndrome. Crit Care Med 1986;14:858-60.

4 Adams FH, Lind J. Physiologic studies on the cardiovascular status of normal newborn infants (with special reference to the ductus arteriosus). Pediatrics 1957;19:431-7.

5 Rudolph AM, Drorbrough JE, Auld PAM, et al. Studies on the circulation in the neonatal period. Pediatrics 1961;27: $551-66$.

6 Young MY, Cottom D. Arterial and venous blood pressure responses during a reduction in blood volume and hypoxia and hypercapnia in infants during the first two days of life. Pediatrics 1966;37:733-42.

7 Burnard ED, James LS. Atrial pressures and cardiac size in the newborn infant. $\mathcal{F}$ Pediatr 1963;62:815-26.

8 Stahlman M, Blankenship WJ, Shepard FM, Gray J, Young WC, Malan AF. Circulatory studies in clinical hyaline

9 Siassi B, Wu PYK Li RK, Mondanlou H. Central venous pressure in preterm infants. Biol Neonate 1980;37:285-90.

10 Cabal L, Hodgman J. Neonatal monitoring: arterial and venous pressure. In: Thibeault DW, Gregory GA, eds. Neonatal pulmonary care. California: Addison-Wesley,

11 Todres DI, Crone RK, Rogers MC, Shannon DC. SwanGanz catheterisation in the critically ill newborn. Crit Care Med 1979;7:330-4.

12 Cabal LA, Devaskar U, Siassi B, Hodgman JE, Emmanouilides G. Cardiogenic shock associated with perinatal asphyxia in preterm infants. $\mathcal{F}$ Pediatr 1980;96: 705-10.

13 Peckham GJ, Fox WW. Physiologic factors affecting pulmonary artery pressure in infants with persistent pulmonary hypertension. $\mathcal{I}$ Pediatr 1978;93:1005-10.

14 Tamura M, Kawano $T$. Effects of intravenous nitroglycerine on hemodynamics in neonates with refractory congestine
heart failure or PFC. Acta Paediatr $\mathcal{f p n} 1990 ; 32: 291-8$.

15 Burnell RH. Venous pressure in congestive heart failure in infancy. Arch Dis Child 1970;45:360-2.

16 Wallgren G, Barr M, Rhude U. Hemodynamic studies of induced acute hypo and hypervolaemia in the newborn induced acute hypo and hypervolaemia in
infant. Acta Paediatr Scand 1964;53:1-12.

17 Moss AJ, Duffie ER, Fagan LM. Respiratory distress in the newborn. Study of the association of cord clamping and the pathogenesis of distress. FAMA 1963;184:170-2.

18 Dobbs HA, Franklin RR, Henly WS, Desmond MM. Blood volume and respiratory distress in the neonate, a preliminary report. Circulation 1961;24:920.

19 Jegier W, Blankenship W, Lind J. Venous pressure in the first hour of life and its relationship to placental transfusion. Acta Paediatr Scand 1963;52:485-96.

20 Miall-Allen VM, De Vries LS, Whitelaw AGL. Mean arterial blood pressure and neonatal cerebral lesions. Arch Dis Child 1987;62:1068-9.

21 Beverley DW, Pitts-Tucker TJ, Congdon PJ, Arthur RJ, Tale G. Prevention of intraventricular haemorrhage by fresh frozen plasma. Arch Dis Child 1985;60:710-3.

22 Pascassi RC. Pediatric intensive care. In: Gregory GA, ed. Pediatric anesthesia. 2nd Ed. California: Churchill LivingPediatric anesthesia.

23 Mackay $R$. Postoperative care of the cardiac patient. In: Lister J, Irving I, eds. Neonatal surgery. 3rd Ed. London Butterworths, 1990:343-64.

24 Milligan DWA. Positive pressure ventilation and cranial volume in newborn infants. Arch Dis Child 1981;56:331-5.

25 Furzan JA, Gabriele G, Wheeler JM, Fixler DE, Rosenfeld CR. Regional blood flows in newborn lambs during endotracheal continuous airway pressure and continuous negative pressure breathing. Pediatr Res 1981;15:874-8.

26 Musewe NN, Poppe D, Smallhorn JF, et al. Doppler echocardiographic measurement of pulmonary artery pressure from ductal Doppler velocities in the newborn. $\mathcal{F}$ Am Coll Cardiol 1990;15:446-56.

27 Evans NJ, Archer LNJ. Postnatal circulatory adaptation in healthy term and preterm neonates. Arch Dis Child 1990;65:24-6.

28 Khoor A, Tulassay $T$, Bald $M$, Rascher W. Changes in plasma concentrations of atrial natriuretic peptide during exchange transfusion in premature infants. Acta Paediatr Scand 1990;79:513-7.

29 Smith A, Prakash P, Nesbitt J, McIntosh N. The vasopressin response to severe birth asphyxia. Early Hum Dev 1990; 22:119-29. 